\title{
Association between rs3087243 and rs231775 polymorphism within the cytotoxic T-lymphocyte antigen 4 gene and Graves' disease: a case/control study combined with meta-analyses
}

\author{
Yaqin Tu${ }^{1, *}$, Guorun Fan ${ }^{1, *}$, Yu Dai ${ }^{3}$, Tianshu Zeng' ${ }^{2}$, Fei Xiao ${ }^{2}$, Lulu Chen ${ }^{2}$ and Wen \\ Kong' \\ ${ }^{1}$ Department of Otorhinolaryngology, Union Hospital, Tongji Medical College, Huazhong University of Science and Technology, \\ Wuhan 430022, China \\ ${ }^{2}$ Department of Endocrinology, Union Hospital, Tongji Medical College, Huazhong University of Science and Technology, \\ Wuhan 430022, China \\ ${ }^{3}$ Department of Nuclear Medicine, Union Hospital, Tongji Medical College, Huazhong University of Science and Technology, \\ Wuhan 430022, China \\ *These authors contributed equally to this work
}

Correspondence to: Wen Kong, email: wenly-kong@163.com

Lulu Chen, email: cheria_chen@126.com

Keywords: Graves' disease; cytotoxic T-lymphocyte antigen 4; polymorphism; susceptibility; case/control study

Received: April 21, 2017

Accepted: October 30, 2017

Published: November 27, 2017

Copyright: Tu et al. This is an open-access article distributed under the terms of the Creative Commons Attribution License 3.0 (CC BY 3.0), which permits unrestricted use, distribution, and reproduction in any medium, provided the original author and source are credited.

\section{ABSTRACT}

We conducted a case/control study to assess the impact of SNP rs3087243 and rs231775 within the CTLA4 gene, on the susceptibility to Graves' disease (GD) in a Chinese Han dataset ( 271 cases and 298 controls). The frequency of $\mathbf{G}$ allele for rs3087243 and rs231775 was observed to be significantly higher in subjects with GD than in control subjects $(p=0.005$ and $p=0.000$, respectively). After logistic regression analysis, a significant association was detected between SNP rs3087243 and GD in the additive and recessive models. Similarly, association for the SNP rs 231775 could also be detected in the additive model, dominant model and recessive model. A meta-analysis, including 27 published datasets along with the current dataset, was performed to further confirm the association. Consistent with our case/control results, rs3087243 and rs231775 showed a significant association with GD in all genetic models. Of note, ethnic stratification revealed that these two SNPs were associated with susceptibility to GD in populations of both Asian and European descent. In conclusion, our data support that the rs3087243 and rs231775 polymorphisms within the CTLA4 gene confer genetic susceptibility to GD.

\section{INTRODUCTION}

Graves' disease (GD) is an autoimmune thyroid disease with a $0.5 \%$ rate of prevalence in the general population [1]. It is characterized by the presence of thyroid-stimulating hormone (TSH) receptor antibodies leading to hyperthyroidism and goiter. The exact etiology of GD remains unknown; however, it is believed that genetic polymorphisms and environmental factors are both involved in pathogenesis. It has now been established that the thyroid gland in patients with GD is infiltrated by lymphocytes, predominantly $\mathrm{T}$ lymphocytes; a $\mathrm{T}$ lymphocyte immune regulating gene cluster is located in the $2 \mathrm{q} 33$ gene region [2-3]. The cytotoxic T-lymphocyte antigen 4 (CTLA4) gene, residing in human chromosome $2 \mathrm{q} 33$, encodes a key negative regulator of T-cell activation and proliferation during the immune response and thereby may influence T-cell mediated autoimmune diseases such as GD [4-5]. Therefore, the CTLA4 gene is a functional candidate genetic marker for studying GD.

Full-length human CTLA4 gene spans $6.1 \mathrm{~kb}$ DNA, with 4 exons and 3 introns. This small region is very polymorphic as manifested by the enrichment of many exonic, intronic, and promoter single nucleotide 
polymorphisms (SNPs). Although the mechanisms underlying CTLA4 mediated GD development are yet to be fully addressed, elucidation of its genetic predisposition to GD, however, may offer some important clues. Indeed, several SNPs within the CTLA4 gene (C/T polymorphism in the promoter region $-318, \mathrm{~A} / \mathrm{G}$ polymorphism in exon $1+49$ (rs231775), microsatellite (AT) repeat in the 3'-UTR of exon 4, and CT60 (rs3087243) in the 6.1-kb $3^{\prime}$ noncoding region (Figure 1) have been suggested to be associated with the development of GD by several genome-wide association studies (GWAS) [6-8]. Nevertheless, the results are somehow inconsistent between the different populations studied. Interestingly, there is plausible evidence indicating that the A to $G$ substitution in exon 1 (rs231775) is possibly linked with T-lymphocyte activation, and the A to G substitution in 3' noncoding region (rs3087243) is possibly associated with the splicing and production efficiency of soluble CTLA4, and indeed, more data consistent with this association have been reported for these two SNPs, especially in Asian populations [9-11]. We, therefore, conducted a case/ control study together with meta-analysis by employing, to our knowledge, all published eligible case/control datasets. We demonstrated convincing evidence supporting the association of rs3087243 and rs231775 polymorphism with increased risk of GD.

\section{RESULTS}

\section{Clinical and biochemical features of the study subjects}

Clinical and biochemical features of the study subjects are summarized in Table 1. In total, 271 patients with GD and 298 ethnically and geographically matched controls were included in this study. No significant differences were observed between patients with GD and control subjects in terms of sex, while the average age of patients with GD was significantly lesser than that of control subjects. However, patients with GD manifested significantly higher levels of FT3, FT4, and TRAB and lower levels of TSH compared to that of control subjects (Table 1).

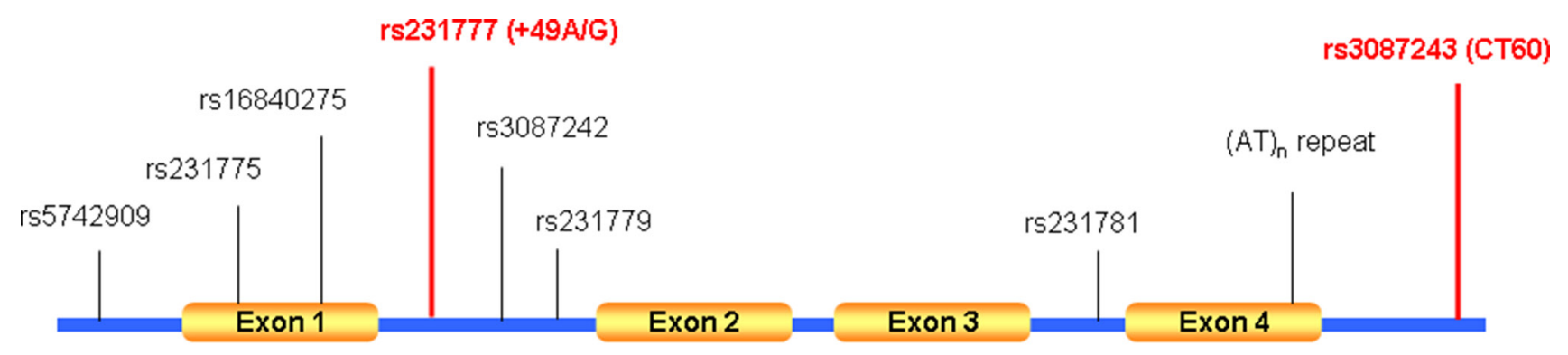

\section{Results for case/control study}

The genotyping results for all patients and controls are summarized in Table 2. The genotypic distribution of SNP rs3087243 and rs231775 was found to be in HardyWeinberg equilibrium for the control subjects $(p>0.05)$. Interestingly, the frequency for $\mathrm{G}$ allele both in rs 3087243 and rs 231775 was observed to be significantly higher in subjects with GD than in control subjects ( $p=0.005$ and $p=0.000$, respectively). After logistic regression analysis, a significant association between SNP rs3087243 and the risk of GD was detected in the additive model $(\mathrm{OR}=1.50$, $95 \% \mathrm{CI}, 1.12-2.00, p=0.007)$ and recessive model $(\mathrm{OR}=1.70,95 \% \mathrm{CI}, 1.19-2.41, p=0.004)$. Similarly, association for the SNP rs231775 could also be detected in the additive model $(\mathrm{OR}=2.66,95 \% \mathrm{CI}, 2.02-3.50$, $p=0.000)$, dominant model (OR $=3.47,95 \% \mathrm{CI}, 1.91$ $6.30, p=0.000)$ and recessive model $(\mathrm{OR}=3.57,95 \%$ CI, 2.51-5.07, $p=0.000)(p<0.025$ was considered with statistical significance after Bonferroni correction, Table 2).

\section{Identification of eligible datasets for meta- analysis}

To further demonstrate the association between the above SNP and GD risk, we next sought to conduct a meta-analysis. In total, 192 publications were relevant to the search words, of which 112 studies were obviously irrelevant, and 15 articles were unacceptable since they were reviews. Additionally, 34 studies were excluded because twenty-three of the articles focused on different genes, another 11 were also excluded because they were not on GD research (5 studies), not a case-control study (4 studies) or polymorphism ( 2 articles). Among the remaining 31 publications, 4 studies were rejected because they either did not present detailed genotyping information ( 3 article) or were published in non-English journals (1 study) (Figure 2).

\section{Characteristics for the selected datasets}

In total, 27 case/control studies were identified based on our selecting criteria. Of which, 13 studies

\section{CTLA-4 gene $(6.1 \mathrm{~kb})$}

Figure 1: The human CTLA4 gene structure and known polymorphisms. 
Table 1: Clinical characteristics for the study subjects

\begin{tabular}{cccc}
\hline Clinical characteristic & GD & Control & P value \\
\hline Number & 271 & 298 & $/$ \\
Sex (\% male) & $25.1 \%$ & $22.8 \%$ & 0.53 \\
Age (years) & $37.3 \pm 15.0$ & $41.4 \pm 14.7$ & 0.001 \\
FT3 (pmol/ml) & $17.0 \pm 13.2$ & $4.9 \pm 0.7$ & $p<0.001$ \\
FT4 (pmol/ml) & $47.5 \pm 27.1$ & $17.4 \pm 2.1$ & $p<0.001$ \\
TSH (mIU/L) & $0.2 \pm 1.0$ & $1.9 \pm 0.9$ & $p<0.001$ \\
TRAB (IU/L) & $12.1 \pm 11.3$ & $0.5 \pm 0.3$ & $p<0.001$ \\
\hline
\end{tabular}

Data are shown as mean \pm standard deviation.

FT3: free triiodothyronine; FT4: free thyroxine; TSH: Thyroid Stimulating Hormone; TRAB: TSH Receptor Antibodies; GD: Graves’ disease

Table 2: Results for case/control study in the Chinese Han population

\begin{tabular}{|c|c|c|c|c|c|c|c|c|}
\hline SNP & \multicolumn{2}{|c|}{ Genotypes } & \multicolumn{2}{|c|}{ Alleles } & & $\boldsymbol{P}_{\text {additive }}$ & $\boldsymbol{P}_{\text {dominant }}$ & $\boldsymbol{P}_{\text {recessive }}$ \\
\hline rs3087243 & $\mathrm{A} / \mathrm{A}$ & $\mathrm{GG}+\mathrm{AG}$ & A & $\mathrm{G}$ & $P$-value & & & \\
\hline GD & 12 & 259 & 89 & 453 & 0005 & 0007 & 0320 & 0004 \\
\hline Control & 18 & 280 & 139 & 457 & $0.00 \mathrm{~J}$ & 0.007 & 0.029 & 0.004 \\
\hline rs231775 & $\mathrm{A} / \mathrm{A}$ & $\mathrm{GG}+\mathrm{AG}$ & A & $\mathrm{G}$ & & & & \\
\hline GD & 16 & 255 & 107 & 435 & 0000 & 0.000 & 0000 & 0.000 \\
\hline Control & 50 & 248 & 241 & 355 & & & & \\
\hline
\end{tabular}

$P$-values were obtained by logistic analyses of three alternative models (additive, dominant, and recessive model) through adjusting for age and gender. $P<0.025$ was considered with statistical significance after Bonferroni correction.

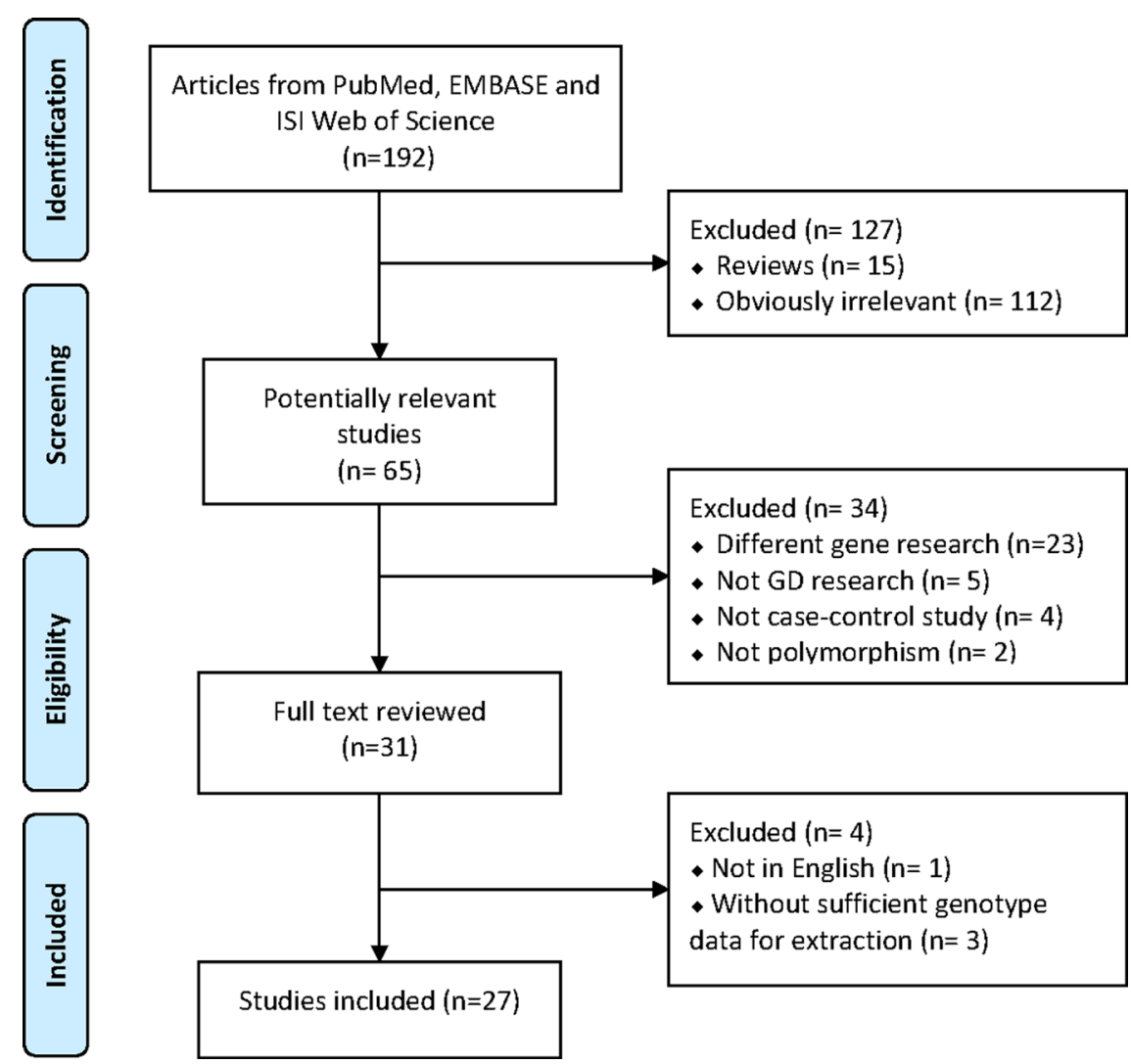

Figure 2: Flow chart for selection of eligible datasets for systematic reviews and meta-analysis (PRISMA). 
were conducted for the rs3087243 polymorphism which included 2299 type 2 diabetic patients and 4176 controls, while 22 studies were carried out for the rs231775 polymorphism which involved 5001 patients and 5774 controls. The principal characteristics and genotype distributions of the identified studies are shown in Table 3. For SNP rs3087243 polymorphism, ten studies came from East Asian [12-21] and three studies from European population [22-24]. For the rs231775 polymorphism, there were 14 studies originated from East Asian [13, $17-$ 21, 25-32], while the rest 8 studies were from European population [6, 23-24, 33-37]. Genotypic distribution for both rs3087243 and rs231775 in controls was in consistent with HWE $(p>0.05)$ except for the 4 datasets highlighted in boldface font in the Table 3 .

\section{Results of the SNP rs3087243 meta-analysis}

Meta-analysis for the SNP rs3087243 was performed by the above identified 13 datasets and our current dataset (2999 cases and 4474 controls in total). Significant association were found in the homozygote model(GG vs. AA: $\mathrm{OR}=2.27,95 \% \mathrm{CI}=1.83-2.82$, $p=0.000)$, heterozygote model (GA vs. AA: $\mathrm{OR}=1.61$, $95 \% \mathrm{CI}=1.30-2.00, p=0.000)$, dominant model $(\mathrm{GG}+$ GA vs. AA: $\mathrm{OR}=1.95,95 \% \mathrm{CI}=1.60-2.40, p=0.000)$, recessive model (GG vs. GA+ AA: $\mathrm{OR}=1.54,95 \%$ $\mathrm{CI}=1.40-1.71, p=0.000)$ and additive model (G vs. A: $\mathrm{OR}=1.49,95 \% \mathrm{CI}=1.37-1.61, p=0.000$ ) (Table 4). For analysis of ethnic stratification, we divided the datasets into 2 subgroups, East Asians and European. Given that no significant genetic heterogeneity was noted, a fixed effects model was thus employed for the analysis. GD susceptibility was significantly detected both in the Asian

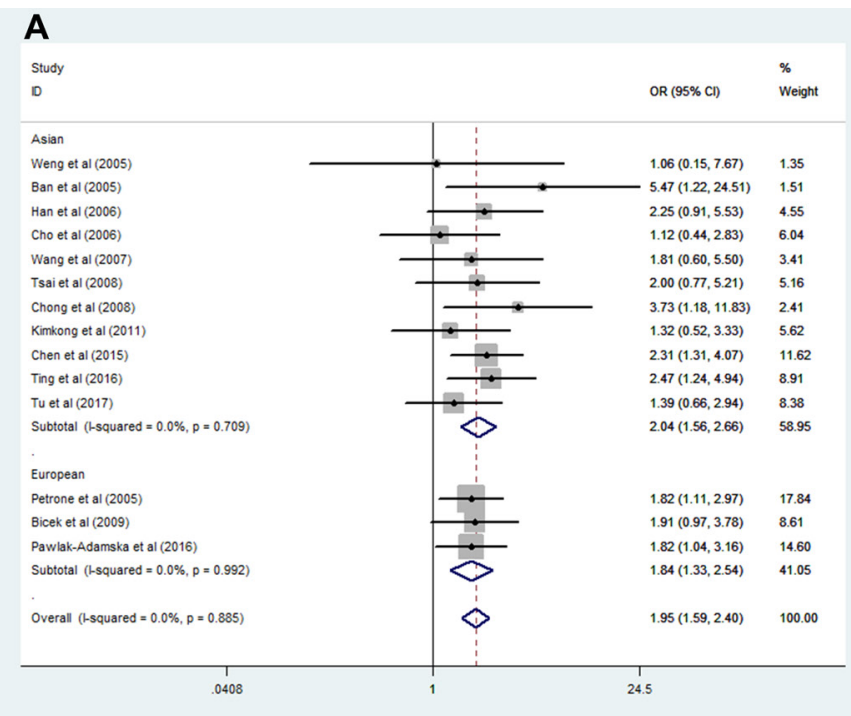

and European descent populations in all genetic models (Figure 3).

\section{Results of the SNP rs231775 meta-analysis}

Next, we conducted a meta-analysis for SNP rs231775 by including 6,115 cases patients and 7,155 controls. A significant association between rs 231775 and GD risk was characterized in the homozygote model (GG vs. AA: OR $=2.41,95 \% \mathrm{CI}=1.91-3.05$, $p=0.000$ ), heterozygote model (GA vs. AA: OR $=1.61,95 \%$ $\mathrm{CI}=1.22-1.74, p=0.000)$, dominant model $(\mathrm{GG}+\mathrm{GA}$ vs. AA: $\mathrm{OR}=1.95,95 \% \mathrm{CI}=1.45-2.06, p=0.000)$, recessive model (GG vs. GA+ AA: OR $=1.54,95 \% \mathrm{CI}=1.47-$ $1.97, p=0.000)$ and additive model ( $\mathrm{G}$ vs. A: OR $=1.49$, $95 \% \mathrm{CI}=1.36-1.65, p=0.000$ ) (Table 4). Analysis of ethnic stratification revealed that the association between rs231775 and GD tended to be much stronger for East Asian than European in all genetic models (Figure 3). Of note, our meta-analysis for SNP rs231775 was hampered by the presence of genetic heterogeneity, which could be due to the differences of ethnicities and geneenvironmental interactions.

\section{Publication bias}

Begg's funnel plot and Egger's test were performed to assess publication bias. The shape of the funnel plots appeared to be symmetrical [SNP rs3087243: (GG + GA) vs. AA; SNP rs231775: GG vs. (GA+ AA)] and the Egger's test did not show any evidence of publication bias (Figure 4). Analysis of sensitivity also revealed that results derived from our study are stable and reliable (data not shown).

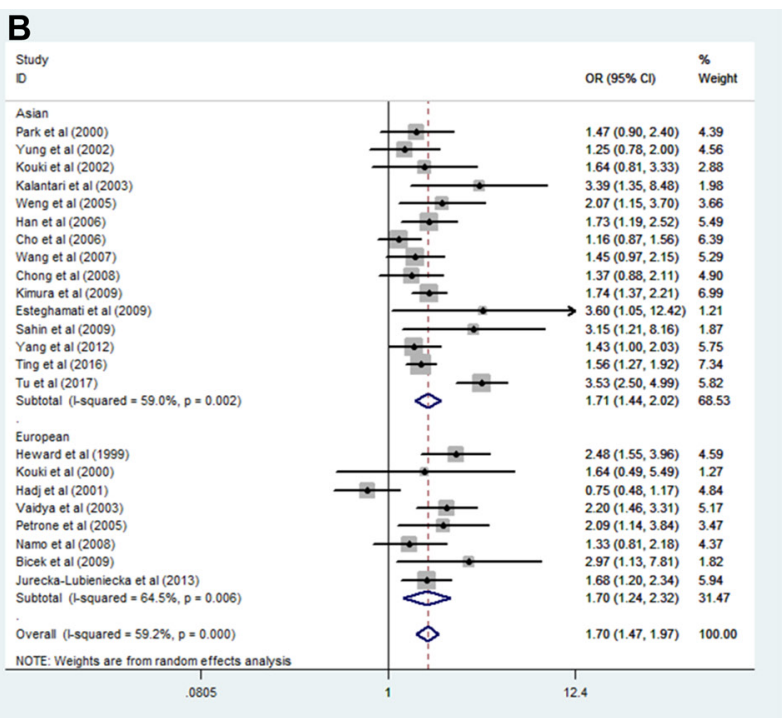

Figure 3: Forest plot for the association of CTLA4 rs3087243 and rs231775 polymorphism with Graves' disease after ethnic stratification. (A) dominant model for SNP rs3087243 [(GG + GA) vs. AA)], (B) recessive model for SNP rs231775 [GG vs. $(\mathrm{GA}+\mathrm{AA})]$. 
Table 3: Summary of datasets included for meta-analysis

\begin{tabular}{|c|c|c|c|c|c|c|c|c|c|c|c|c|c|c|}
\hline \multirow{2}{*}{ ID } & \multirow{2}{*}{ Author } & \multirow{2}{*}{ Year } & \multirow{2}{*}{ Ethnicity } & \multirow{2}{*}{$\begin{array}{c}\text { Genotyping } \\
\text { method }\end{array}$} & \multirow{2}{*}{$\begin{array}{l}\text { Study } \\
\text { design }\end{array}$} & \multirow{2}{*}{ SNP loc } & \multirow{2}{*}{$\begin{array}{c}\text { Case/ } \\
\text { Control }\end{array}$} & \multicolumn{3}{|c|}{ GD genotype } & \multicolumn{3}{|c|}{ Control genotype } & \multirow{2}{*}{$p \mathrm{HWE}$} \\
\hline & & & & & & & & $\mathbf{A A}$ & AG & GG & $\mathbf{A A}$ & AG & GG & \\
\hline 1 & Heward et al. & 1999 & European & PCR-RFLP & $\mathrm{CC}$ & rs231775 & $379 / 363$ & 122 & 192 & 65 & 164 & 171 & 28 & 0.07 \\
\hline 2 & Park et al. & 2000 & Asian & PCR-RFLP & $\mathrm{CC}$ & rs231775 & $97 / 199$ & 5 & 35 & 57 & 26 & 75 & 98 & 0.06 \\
\hline 3 & Kouki et al. & 2000 & European & PCR-RFLP & $\mathrm{CC}$ & rs 231775 & $45 / 43$ & 8 & 29 & 8 & 15 & 23 & 5 & 0.39 \\
\hline 4 & Hadj et al. & 2001 & European & PCR-RFLP & $\mathrm{CC}$ & rs231775 & $144 / 205$ & 31 & 63 & 50 & 26 & 94 & 85 & 0.99 \\
\hline 5 & Kouki et al. & 2002 & Asian & PCR-RFLP & $\mathrm{CC}$ & rs 231775 & $120 / 80$ & 22 & 67 & 31 & 30 & 36 & 14 & 0.58 \\
\hline 6 & Yung et al. & 2002 & Asian & SSCP & $\mathrm{CC}$ & rs 231775 & $123 / 158$ & 3 & 54 & 66 & 23 & 36 & 14 & 0.99 \\
\hline 7 & Vaidya et al. & 2003 & European & PCR-RFLP & $\mathrm{CC}$ & rs 231775 & $301 / 349$ & 88 & 139 & 74 & 146 & 158 & 45 & 0.83 \\
\hline 8 & Kalantari et al. & 2003 & Asian & PCR-RFLP & $\mathrm{CC}$ & rs 231775 & $90 / 90$ & 21 & 49 & 20 & 30 & 53 & 7 & 0.013 \\
\hline \multirow[t]{2}{*}{9} & \multirow[t]{2}{*}{ Petrone et al. } & \multirow{2}{*}{2005} & \multirow[t]{2}{*}{ European } & \multirow[t]{2}{*}{ Taqman } & \multirow[t]{2}{*}{$\mathrm{CC}$} & rs3087243 & \multirow{2}{*}{$150 / 301$} & 26 & 79 & 45 & 83 & 149 & 69 & 0.89 \\
\hline & & & & & & rs231775 & & 59 & 68 & 23 & 139 & 138 & 24 & 0.201 \\
\hline \multirow{2}{*}{10} & \multirow{2}{*}{ Weng et al. } & \multirow{2}{*}{2005} & \multirow{2}{*}{ Asian } & PCR-RFLP & $\mathrm{CC}$ & & $107 / 101$ & 2 & 27 & 78 & 2 & 45 & 54 & 0.033 \\
\hline & & & & & & rs 231775 & $104 / 101$ & 5 & 53 & 46 & 15 & 58 & 28 & 0.091 \\
\hline 11 & Ban et al. & 2005 & Asian & PCR-RFLP & $\mathrm{CC}$ & rs3087243 & $131 / 179$ & 2 & 38 & 91 & 14 & 70 & 95 & 0.83 \\
\hline 12 & Cho et al. & 2006 & Asian & Sequencing & $\mathrm{CC}$ & rs 3087243 & $283 / 472$ & 7 & 78 & 198 & 13 & 125 & 334 & 0.75 \\
\hline & & & & & & rs 231775 & $288 / 471$ & 16 & 112 & 160 & 30 & 197 & 244 & 0.24 \\
\hline 13 & Han etal & 2006 & Asian & DCFH & $\mathrm{CC}$ & rs3087243 & $261 / 196$ & 8 & 71 & 182 & 13 & 60 & 123 & 0.14 \\
\hline & & & & & & rs 231775 & $261 / 196$ & 32 & 94 & 135 & 32 & 89 & 75 & 0.52 \\
\hline 14 & Wang et al & 2007 & Asion & PCR_PFI P & $C \Gamma$ & rs3087243 & 189/192 & 5 & 46 & 138 & 9 & 58 & 125 & 0.50 \\
\hline 17 & 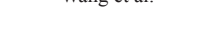 & 2001 & Hovint & (2) & e & rs 231775 & $208 / 192$ & 15 & 69 & 124 & 18 & 77 & 97 & 0.63 \\
\hline 15 & Chong et al. & 2008 & Asian & Tagman & $\mathrm{CC}$ & rs3087243 & $177 / 151$ & 4 & 48 & 125 & 12 & 51 & 88 & 0.24 \\
\hline & & & & & & rs 231775 & & 7 & 73 & 97 & 24 & 56 & 71 & 0.03 \\
\hline 16 & Tsai et al. & 2008 & Asian & PCR-RFLP & $\mathrm{CC}$ & rs3087243 & $189 / 192$ & 5 & 48 & 136 & 9 & 58 & 125 & 0.50 \\
\hline 17 & Namo et al. & 2008 & European & PCR-RFLP & $\mathrm{CC}$ & rs231775 & $217 / 149$ & 116 & 43 & 58 & 78 & 39 & 32 & 0.000 \\
\hline 18 & Sahin et al. & 2009 & Asian & PCR-RFLP & $\mathrm{CC}$ & rs 231775 & $77 / 98$ & 29 & 33 & 15 & 43 & 48 & 7 & 0.19 \\
\hline 19 & Esteghamati et al. & 2009 & Asian & PCR-RFLP & $\mathrm{CC}$ & rs 231775 & $205 / 103$ & 114 & 71 & 20 & 75 & 25 & 3 & 0.61 \\
\hline 20 & Kimura et al. & 2009 & Asian & PCR-RFLP & $\mathrm{CC}$ & rs 231775 & $415 / 795$ & 62 & 143 & 210 & 142 & 358 & 295 & 0.07 \\
\hline 21 & Bicek et al & 2009 & Furonean & Tagman & $\mathrm{CC}$ & rs3087243 & $123 / 117$ & 16 & 57 & 50 & 26 & 61 & 30 & 0.63 \\
\hline & Dic & 2007 & 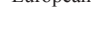 & 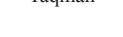 & & rs 231775 & & 33 & 73 & 17 & 47 & 64 & 6 & 0.01 \\
\hline 22 & Kimkong et al. & 2011 & Asian & PCR-RFLP & $\mathrm{CC}$ & rs3087243 & $132 / 153$ & 8 & 46 & 78 & 12 & 59 & 82 & 0.76 \\
\hline 23 & Yang et al. & 2012 & Asian & PCR-RFLP & $\mathrm{CC}$ & rs 231775 & $303 / 215$ & 12 & 139 & 152 & 29 & 97 & 89 & 0.75 \\
\hline 24 & Jurecka-Lubieniecka & 2013 & European & PCR-RFLP & $\mathrm{CC}$ & rs 231775 & $620 / 340$ & 159 & 302 & 159 & 126 & 156 & 58 & 0.42 \\
\hline 25 & Chen et al. & 2015 & Asian & PCR-HRM & $\mathrm{CC}$ & rs3087243 & $260 / 248$ & 20 & 100 & 140 & 40 & 101 & 107 & 0.056 \\
\hline 26 & Pawlak-Adamska et al. & 2016 & European & PCR-RFLP & $\mathrm{CC}$ & rs3087243 & $172 / 388$ & 18 & 80 & 74 & 68 & 187 & 133 & 0.87 \\
\hline 27 & Ting et al. & 2016 & Asian & PCR-RFLP & $\mathrm{CC}$ & rs3087243 & $554 / 1058$ & 10 & 149 & 395 & 46 & 382 & 630 & 0.21 \\
\hline & & & & & & rs 231775 & & 34 & 209 & 311 & 112 & 469 & 477 & 0.84 \\
\hline Our & Tuet & 2017 & A sion & Sequencing & $\left.C C^{\prime}\right)$ & rs3087243 & $271 / 298$ & 12 & 65 & 194 & 18 & 103 & 177 & 0.56 \\
\hline study & & & & & & rs231775 & $271 / 298$ & 16 & 75 & 180 & 50 & 141 & 107 & 0.76 \\
\hline
\end{tabular}

CC: case/control

HWE: Hardy-Weinberg equilibrium

DCFH: Dual-color fluorescence hybridization technique

PCR-HRM: Polymerase chain reaction-high resolution melting

\section{DISCUSSION}

Cytotoxic T-lymphocyte antigen 4 encoded by the CTLA4 gene is involved in controlling the proliferation and apoptosis of $\mathrm{T}$ lymphocytes, which is an essential contributing factor for the development of GD. Since the recognition of this functional property of CTLA4, it has been considered a candidate gene for GD. Nevertheless, thus far, no consistent results have been reported in terms of its genetic predisposition in GD pathoetiology. To address this issue, we conducted a case/control study focusing on the two SNPs, rs3087243 located in 3' UTR and rs231775 located in exon 1 within the CTLA4 gene, which included 271 patients with GD and 298 matched controls. Meta-analysis using the 27 published datasets along with our current study dataset was performed next to confirm the association further. Collectively, our study reported convincing evidence that SNP rs3087243 and rs231775 within CTLA4 predisposes subjects with an increased risk of developing GD.

In our case/control study, the $G$ allele frequency for both rs3087243 and rs231775 was observed to be significantly higher in patients with GD than in the control subjects suggesting that the $G$ allele may confer 
an increased risk of GD. Indeed, a significant association was detected between the $G$ allele of rs3087243 and susceptibility to GD in the additive and recessive models. Similarly, association for the SNP rs231775 could also be detected in the additive model, dominant model and recessive model after Bonferroni correction. Of note, there was a significant difference in terms of average age between patients with GD and control subjects in our dataset. This discrepancy is most likely caused by the impact of age on the risk of GD. The impact of genetic factors may be higher than environmental factors in patients with young age at GD diagnosis. Many studies have reported that GD occurs more frequently in young female patients. For example, Wang and colleagues reported that the average age of patients GD was significantly lesser than that of the control group [18]. Given that aging may induce reduction in the presence or intensity of signs and symptoms of the disease, it could be more difficult to diagnose hyperthyroidism [38]. Consistent with our observations, similar differences in average ages were also noted in other published datasets [18, 20, 39].

Our subsequent meta-analysis using 27 published datasets and our current study dataset provided additional evidence for the association between the two SNPs (rs3087243 and rs231775) and the risk of GD. To determine the influence of population stratification, we then divided all the datasets into two subgroups, East Asian and European descent. We found that rs3087243 and rs231775 polymorphism were associated with susceptibility to GD in both the Asian and European descent populations in all genetic models. These results were consistent with those reported by Chong et al. and Ting et al. from two other independent Chinese Han datasets. However, Kimkong and his colleagues failed to detect the association between CTLA4 CT60 polymorphism and GD in Thai population [40]. Given that factors such as living style and diet, social and emotional stress, as well as medical care and economic conditions are

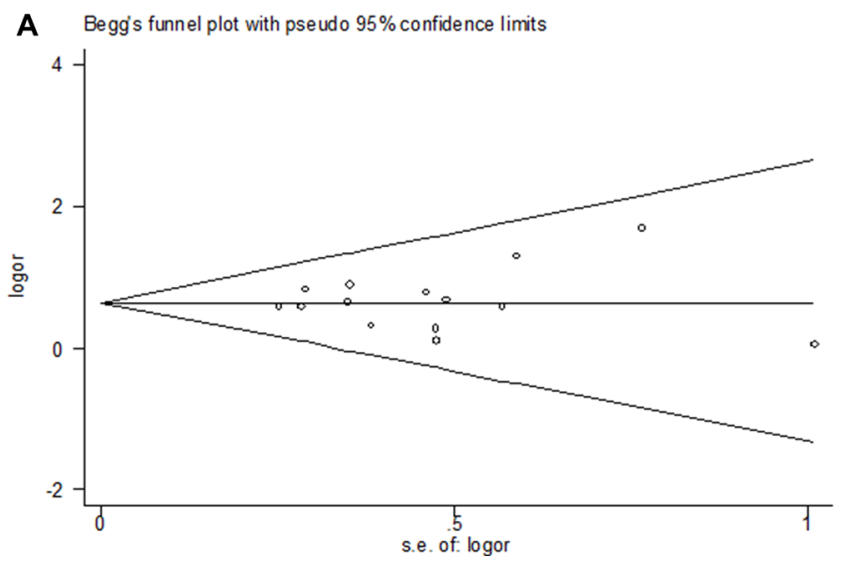

likely to be very diverse between each population group, heterogeneity could therefore be present even within the same ethnic group [41]. Of course, other factors such as study design and limited sample size may also contribute to the study discrepancies.

SNP rs3087243 is located downstream of the poly (A) termination site. Previous studies have suggested that this polymorphism is important for efficient splicing and production of soluble CTLA4 (sCTLA4), and may play a role in the mRNA stability of SCTLA4. In line with this notion, subjects with the putative risk $\mathrm{G} / \mathrm{G}$ genotype have lower production of sCTLA4 than that by subjects with the protective A/A genotype [11]. The soluble form of CTLA4 is translated and secreted in human serum and can bind to CD80/86 molecules. Recombinant sCTLA4 inhibits T-cell proliferation in vitro, indicating that a reduction in the levels of this form of CTLA4 could lead to inefficient blocking of the immune response, triggering an autoimmune disorder [42]. The exonic SNP rs231775 in the CTLA4 leader peptide results in threonine to alanine change, and researchers found that the polymorphism decreased CTLA4 cell surface expression and reduced the inhibitory function of CTLA4, and the $\mathrm{G}$ allele reduced the ability to control T-cell proliferation [43-45]. Therefore, this might confer a lesser CTLA4 function, resulting in greater T-cell activity, stronger immune response, and a higher probability of autoimmunity.

Despite that we employed a comprehensive analytic strategy to conduct our current studies; some issues are probably still needed to be pointed out. First, although our systematic meta-analysis with sufficient statistical power demonstrated a consistent conclusion as our case/ control data, the sample size for our case/control dataset was relatively small. Second, the cases were significantly younger than the controls. It is merely due to selection bias. Considering this bias would lead to false positivity or false negativity, we will explore the association between these polymorphism and GD after age stratification in

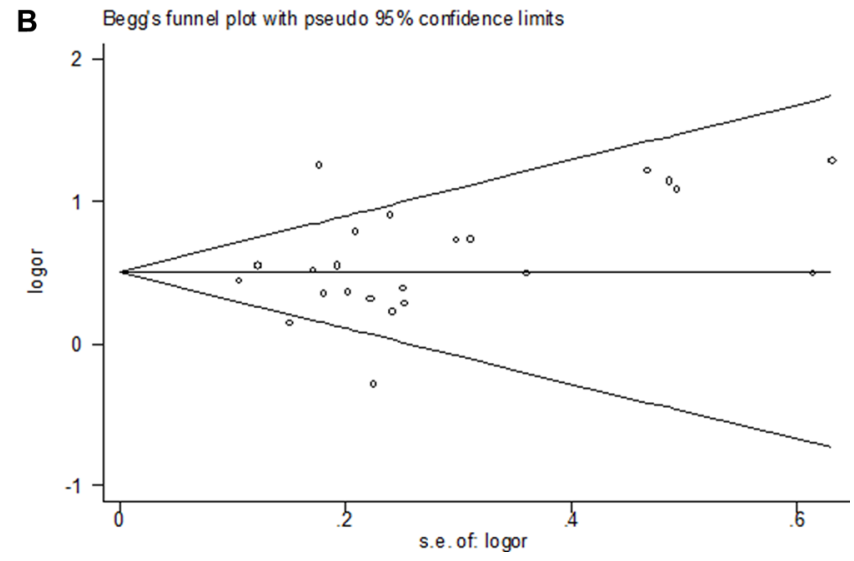

Figure 4: Funnel plot analysis to detect publication bias. Each point represents a separate study for the indicated association. (A) Begg's funnel of publication bias test for SNP rs3087243: [(GG+GA) vs. AA)]; (B) Begg's funnel of publication bias test for SNP rs231775: [GG vs. (GA+AA)]. 
Table 4: Results for meta-analysis of CTLA4 polymorphisms with Graves' disease risk

\begin{tabular}{|c|c|c|c|c|c|}
\hline \multirow{2}{*}{ SNPs } & \multirow{2}{*}{ OR(95\% CI) } & \multirow{2}{*}{$p$ value } & \multicolumn{2}{|c|}{ Test of heterogeneity } & \multirow{2}{*}{$\begin{array}{c}p \text { for publication } \\
\text { bias }^{\mathrm{a}}\end{array}$} \\
\hline & & & $\mathbf{I}^{2}$ & $p$ value & \\
\hline \multicolumn{6}{|l|}{ rs3087243 $(\mathrm{A}>\mathrm{G})$} \\
\hline GG vs. AA & $2.27[1.83,2.82]$ & 0.000 & $0.0 \%$ & 0.822 & 0.779 \\
\hline GA vs. AA & $1.61[1.30,2.00]$ & 0.000 & $0.0 \%$ & 0.931 & 0.675 \\
\hline $\mathrm{GG}+\mathrm{GA}$ vs. $\mathrm{AA}$ & $1.95[1.60,2.40]$ & 0.000 & $0.0 \%$ & 0.885 & 0.753 \\
\hline GG vs. GA + AA & $1.54[1.40,1.71]$ & 0.000 & $14.5 \%$ & 0.294 & 0.543 \\
\hline G vs. A allele & $1.49[1.37,1.61]$ & 0.000 & $11.7 \%$ & 0.325 & 0.601 \\
\hline \multicolumn{6}{|l|}{$\operatorname{rs} 231775(\mathrm{~A}>\mathrm{G})$} \\
\hline GG vs. AA & $2.41[1.91,3.05]$ & 0.000 & $64.0 \%$ & 0.000 & 0.058 \\
\hline GA vs. AA & $1.46[1.22,1.74]$ & 0.000 & $56.9 \%$ & 0.000 & 0.084 \\
\hline $\mathrm{GG}+\mathrm{GA}$ vs. $\mathrm{AA}$ & $1.73[1.45,2.06]$ & 0.000 & $61.1 \%$ & 0.000 & 0.072 \\
\hline GG vs. GA + AA & $1.70[1.47,1.97]$ & 0.000 & $59.2 \%$ & 0.000 & 0.251 \\
\hline G vs. A allele & $1.50[1.36,1.65]$ & 0.000 & $61.9 \%$ & 0.000 & 0.687 \\
\hline
\end{tabular}

${ }^{a}$ Egger's test was performed to assess publication bias.

the future study. Third, we do not have enough data for assessing the differences of gene-environment interactions. Therefore, additional studies with a large dataset along with informative data for assessing the differences of gene - environmental interactions would be necessary.

In summary, our case/control study combined with meta-analysis provided convincing evidence that the CTLA4 polymorphisms confer genetic susceptibility to GD in the Chinese Han population. Specifically, the rs3087243 and rs231775 within the CTLA4 gene are more susceptible to the genetic predisposition of GD. Future studies in a large dataset and focused on addressing the functional relevance of this polymorphism within the CTLA4 gene would be necessary for fully establishing the impact on susceptibility to GD.

\section{MATERIALS AND METHODS}

\section{Study subjects}

We studied 271 Chinese patients with GD $(37.3 \pm$ 15.0 years old, 68 males and 203 females) recruited from the department of Endocrinology and 298 ethnically and geographically matched controls $(41.4 \pm 14.7$ years old, 68 males and 230 females) from the Physical examination center, Union Hospital of Huazhong, University of Science and Technology. GD was diagnosed according to the clinical and laboratory features including (1) Biochemical assessment of hyperthyroidism (raised serum fT3 or fT4 levels, suppressed serum thyrotropin: TSH levels); (2) diffuse enlargement of thyroid gland; (3) presence of antithyroglobulin antibodies; and (4) other related symptoms such as exophthalmos and pretibial myxedema.
The combination of diffuse goiter and prolonged hyperthyroidism is nearly always caused by Graves' disease, and the presence of characteristic eye or skin changes is diagnostic. Documentation of elevated TRAB can confirm the diagnosis. The normal reference range of indicators were as follows: TSH: $0.27-4.2 \mathrm{mIU} / \mathrm{L}$; free T4 (fT4): $12-22 \mathrm{pmol} / \mathrm{L}$; and free T3 (fT3): 3.1-6.8 pmol/L; TRAB: $0-1.75 \mathrm{IU} / \mathrm{L}$. Control subjects with a family history of type 1 diabetes, autoimmune thyroid disease, or any other autoimmune diseases were excluded. All participants provided written informed consent. This study complied with the principles of the Declaration of Helsinki and was approved by the Institutional Review Board (IRB) and the ethics committees of the Union Hospital of Huazhong, University of Science and Technology.

\section{DNA isolation and genotyping}

Genomic DNA was extracted from $1 \mathrm{ml}$ of peripheral blood sample of each subject using a genomic DNA extraction kit (TianGen, China) and according to the manufacturer's instructions. Genotyping of the rs3087243 and rs231775 polymorphism was performed by direct sequencing with an $\mathrm{ABI}$ 3730XL genetic analyzer (Applied Biosystems, Foster City, CA, USA) (Figure 5). These primers are as follows: rs3087243: Forward - CTT CAT GAG TCA GCT TTG CAC CAG C

Reverse - AGC TGA GAA AGC AGG CGG TAA GAA A

rs231775: Forward - GCT CTA CTT CCT GAA GAC CT

Reverse - AGT CTC ACT CAC CTT TGC AG 


\section{Thyroid function tests and determination of autoantibodies}

The serum concentrations of FT3 (Roche Diagnostics GmbH, Mannheim, Germany), FT4 (Roche Diagnostics GmbH, Mannheim, Germany), TSH (Roche Diagnostics GmbH, Mannheim, Germany), and TRAB(Roche Diagnostics GmbH, Mannheim, Germany) were measured by commercial kits and Roche cobas e601 fully automated immunochemistry analyzer.

\section{Statistical analysis}

Comparison of biochemical data between GD patients and control subjects was carried out by $t$ tests. The Pearson's $\chi^{2}$ test was used to analyze the frequencies of genotypes between cases and controls. Hardy-Weinberg equilibrium (HWE) was evaluated by the goodness-of-fit $\chi^{2}$ test for genotypes in the control group. Unconditional multivariate logistic regression analysis was used to estimate odds ratios (ORs) and their 95\% confidence intervals (CIs) after adjusting for sex and age. The statistical power of the study was calculated using PowerV3.0 software (http://www.mds.qmw.ac.uk/statgen/dcurtis/software. html). For SNPs with minor allele frequency (MAF) of 0.2 , the power of our sample size was calculated to be 0.943 for detecting an OR of 1.91 in the case control study. This assumption on an OR was based on two different studies, which conducted on the Taiwan population and Slovenian population (OR of 1.91 and 2.0, respectively). All those statistical analyses were performed by means of the SPSS 18.0 software (SPSS Inc. Chicago, IL, USA). For the purpose of correcting for multiple testing, Bonferroni correction was applied. Consequently, differences were considered significant when the $p$ value was less than 0.025 .

\section{Meta analysis}

PubMed, EMBASE and ISI Web of Science were searched (the last search was conduct on March 1, 2017) using the following search terms: "CTLA4" or "Cytotoxic T-Lymphocyte-Associated Antigen 4" and "Graves' disease" and "polymorphism". Reference, which were listed in each identified article, were also searched manually to identify additional eligible studies. To be eligible, the following inclusion criteria were established: (1) a human case-control study of a polymorphism associated with Graves' disease; (2) studies that included sufficient genotype data for extraction. Main exclusion criteria of studies were as follows: (1) case reports, letters, reviews, and editorial articles; (2) literature not containing information regarding Graves' disease research; (3) study involving only a case population; and (4) study not written in English. In the case of multiple studies by the same researchers involving the same or overlapping data sets, we selected the most recent study with the largest number of participants.

Two curators (Yaqin $\mathrm{Tu}$ and Guorun Fan) independently extracted information from included studies. Disagreement was resolved by discussion between the two authors. The following data were extracted: first author's name, year of publication, the ethnicities of the
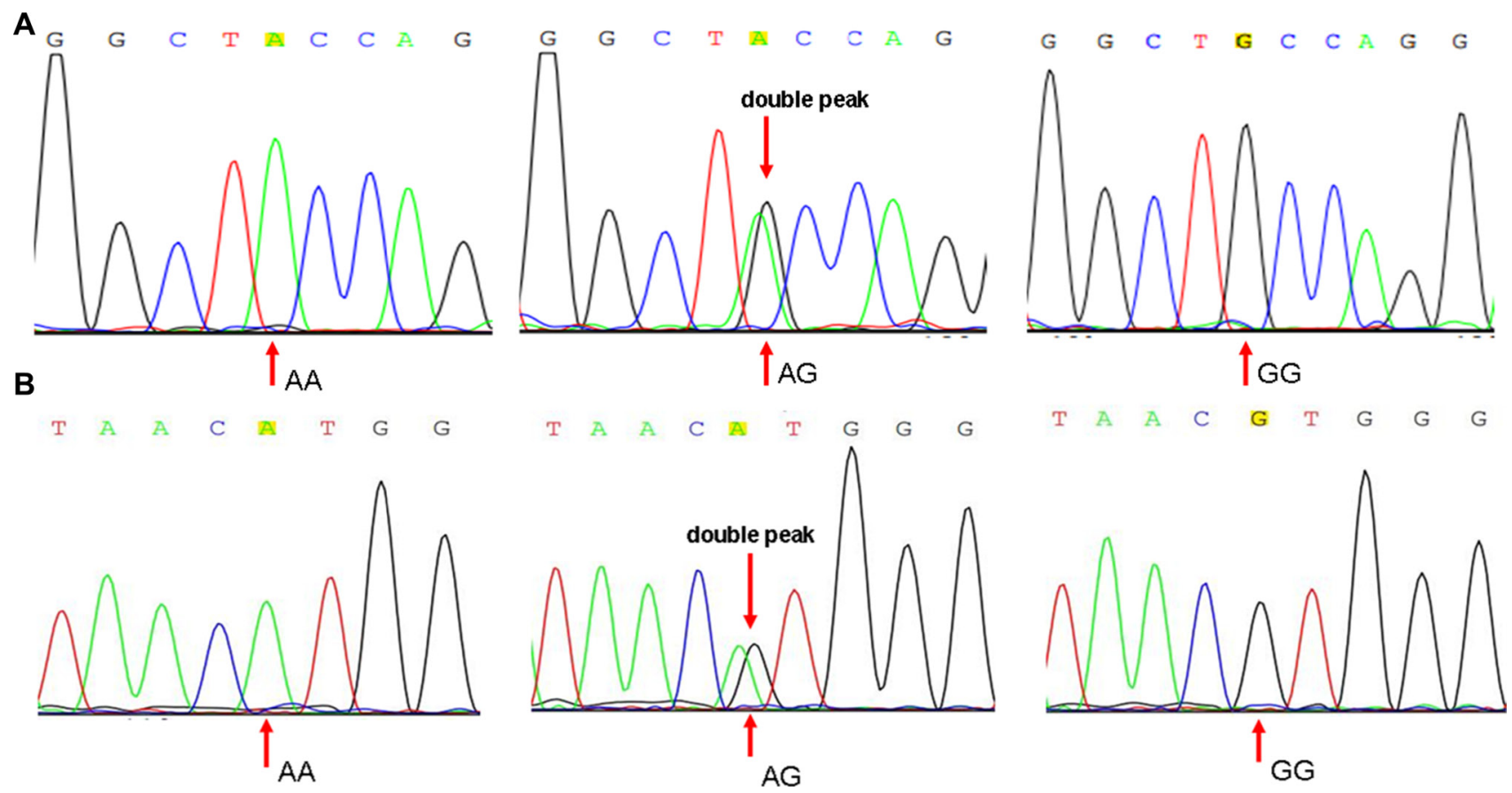

Figure 5: Sequence diagrams of SNP rs3087243 and rs231775. (A) Sequence diagrams of rs231775; (B) Sequence diagrams of rs3087243. 
individuals involved, the genotyping method, number of cases and controls for each genotype, and the HardyWeinberg equilibrium (HWE) among the controls. Ethnicity was categorized as East Asian and European. A double-check procedure was performed to ensure accuracy of data entry.

The strength of associations between SNP rs3087243 and rs231775 within the CTLA4 gene and Graves' disease risk was measured by ORs with $95 \%$ CIs. We explored the association between rs3087243 and Graves' disease in homozygote model (GG vs. AA), heterozygote model (GA vs. AA), dominant model [(GG $+\mathrm{GA})$ vs. AA)], recessive model [GG vs. (GA + AA)] and additive model (G vs. A), respectively. The same genetic models were applied for SNP rs231775 as well. The Chi-squared-based Q-statistic test was used to assess the between-study heterogeneity, and it was considered significant if $P<0.10$. When the effects were assumed to be homogenous, fixed-effects model was used (the Mantel-Haenszel method); otherwise, it was more appropriate to use random-effects model (DerSimonian and Laird method). Sensitivity analysis was performed to assess the influence of each individual study by omitting 1 study at a time and calculating a pooled estimate for the remainder of the studies. The inverted funnel plots and Egger's regression test were used to investigate publication bias. Potential publication bias was assessed with funnel plots of the effect sizes versus the standard errors; Begg's test was used to identify significant asymmetry. If there is evidence of publication bias, funnel plot is noticeably asymmetric. Concerning the significance level of the Begg's and Egger's tests was set at 0.05. All statistical tests carried out in the present report were two tailed and all analyses were conducted using the STATA 11.0 software (STATA Corporation, College Station, TX, USA).

\section{Abbreviations}

GD: Graves' disease; CTLA4: Cytotoxic T-lymphocyte antigen 4; TSH: thyroid-stimulating hormone; GWAS: genome-wide association studies; CI: confidence interval; OR: odds ratio; SNPs: single nucleotide polymorphisms; HWE: Hardy-Weinberg equilibrium; TRAB: TSH Receptor Antibodies.

\section{Author contributions}

Conceived and designed the study strategy: W.K., L.L.C; Acquisition of data: statistical analysis and interpretation of data Y.Q.T., G.R.F.; Drafting or revision of the manuscript: Y.Q.T., G.R.F.; Reference collection and data management: Y.D., T.S.Z.; Wrote the manuscript: Y.Q.T.; Prepared the tables and figures: F.X.; Study supervision: W.K., L.L.C; All authors reviewed the manuscript.

\section{CONFLICTS OF INTEREST}

The authors declare that they have no conflicts of interest.

\section{FUNDING}

This work was supported by the National Natural Science Foundation of China (No. 81500796 and No. 81500620).

\section{REFERENCES}

1. Vanderpump MP, Tunbridge WM, French JM, Appleton D, Bates D, Clark F, Grimley Evans J, Hasan DM, Rodgers $\mathrm{H}$, Tunbridge F, Young ET. The incidence of thyroid disorders in the community: a twenty-year follow-up of the Whickham Survey. Clin Endocrinol (Oxf). 1995; 43:55-68.

2. Vaidya B, Imrie H, Perros P, Young ET, Kelly WF, Carr D, Large DM, Toft AD, McCarthy MI, Kendall-Taylor P, Pearce SH. The cytotoxic T lymphocyte antigen-4 is a major Graves' disease locus. Hum Mol Genet. 1999; 8:1195-1199.

3. Vaidya B, Imrie H, Perros P, Dickinson J, McCarthy MI, Kendall-Taylor P, Pearce SH. Cytotoxic T lymphocyte antigen-4 (CTLA-4) gene polymorphism confers susceptibility to thyroid associated orbitopathy. Lancet. 1999; 354:743-744.

4. Anderson DE, Bieganowska KD, Bar-Or A, Oliveira EM, Carreno B, Collins M, Hafler DA. Paradoxical inhibition of T-cell function in response to CTLA-4 blockade; heterogeneity within the human T-cell population. Nat Med. 2000; 6:211-214.

5. Gough SC, Walker LS, Sansom DM. CTLA4 gene polymorphism and autoimmunity. Immunol Rev. 2005; 204:102-115.

6. Vaidya B, Oakes EJ, Imrie H, Dickinson AJ, Perros P, Kendall-Taylor P, Pearce SH. CTLA4 gene and Graves' disease: association of Graves' disease with the CTLA4 exon 1 and intron 1 polymorphisms, but not with the promoter polymorphism. Clin Endocrinol (Oxf). 2003; 58:732-735.

7. Kotsa K, Watson PF, Weetman AP. A CTLA-4 gene polymorphism is associated with both Graves disease and autoimmune hypothyroidism. Clin Endocrinol (Oxf). 1997; 46:551-554.

8. Donner H, Braun J, Seidl C, Rau H, Finke R, Ventz M, Walfish PG, Usadel KH, Badenhoop K. Codon 17 polymorphism of the cytotoxic $\mathrm{T}$ lymphocyte antigen 4 gene in Hashimoto's thyroiditis and Addison's disease. J Clin Endocrinol Metab. 1997; 82:4130-4132.

9. van Belzen MJ, Mulder CJ, Zhernakova A, Pearson PL, Houwen RH, Wijmenga C. CTLA4 +49 A/G and CT60 polymorphisms in Dutch coeliac disease patients. Eur J Hum Genet. 2004; 12:782-785. 
10. Daroszewski J, Pawlak E, Karabon L, Frydecka I, Jonkisz A, Slowik M, Bolanowski M. Soluble CTLA-4 receptor an immunological marker of Graves' disease and severity of ophthalmopathy is associated with CTLA-4 Jo31 and CT60 gene polymorphisms. Eur J Endocrinol. 2009; 161:787-793.

11. Ueda H, Howson JM, Esposito L, Heward J, Snook H, Chamberlain G, Rainbow DB, Hunter KM, Smith AN, Di Genova G, Herr MH, Dahlman I, Payne F, et al. Association of the T-cell regulatory gene CTLA4 with susceptibility to autoimmune disease. Nature. 2003; 423:506-511.

12. Ban Y, Tozaki T, Taniyama M, Tomita M. Association of a CTLA-4 3' untranslated region (CT60) single nucleotide polymorphism with autoimmune thyroid disease in the Japanese population. Autoimmunity. 2005; 38:151-153.

13. Ting WH, Chien MN, Lo FS, Wang CH, Huang CY, Lin CL, Lin WS, Chang TY, Yang HW, Chen WF, Lien YP, Cheng $\mathrm{BW}$, Lin $\mathrm{CH}$, et al. Association of Cytotoxic T-LymphocyteAssociated Protein 4 (CTLA4) Gene Polymorphisms with Autoimmune Thyroid Disease in Children and Adults: Case-Control Study. PLoS One. 2016; 11:e0154394.

14. Chen X, Hu Z, Li W, Wu P, Liu M, Bao L, Wu M, Fang S, Xiong W, Chen M, Wu G. Synergistic combined effect between CD40-1C $>$ T and CTLA-4+6230G $>$ A polymorphisms in Graves' disease. Gene. 2015; 567:154-158.

15. Kimkong I, Nakkuntod J, Sae-Ngow S, Snabboon T, Avihingsanon Y, Hirankarn N. Association between CTLA4 polymorphisms and the susceptibility to systemic lupus erythematosus and Graves' disease in Thai population. Asian Pac J Allergy Immunol. 2011; 29:229-235.

16. Tsai ST, Huang CY, Lo FS, Chang YT, Tanizawa T, Chen CK, Wang ZC, Liu HF, Chu CC, Lin M, Lin CH, Li HJ, Lee YJ. Association of CT60 polymorphism of the CTLA4 gene with Graves' disease in Taiwanese children. J Pediatr Endocrinol Metab. 2008; 21:665-672.

17. Chong KK, Chiang SW, Wong GW, Tam PO, Ng TK, Hu YJ, Yam GH, Lam DS, Pang CP. Association of CTLA-4 and IL-13 gene polymorphisms with Graves' disease and ophthalmopathy in Chinese children. Invest Ophthalmol Vis Sci. 2008; 49:2409-2415.

18. Wang PW, Chen IY, Liu RT, Hsieh CJ, Hsi E, Juo SH. Cytotoxic $\mathrm{T}$ lymphocyte-associated molecule-4 gene polymorphism and hyperthyroid Graves' disease relapse after antithyroid drug withdrawal: a follow-up study. J Clin Endocrinol Metab. 2007; 92:2513-2518.

19. Han S, Zhang S, Zhang W, Li R, Li Y, Wang Z, Xie Y, Mao Y. CTLA4 polymorphisms and ophthalmopathy in Graves' disease patients: association study and meta-analysis. Hum Immunol. 2006; 67:618-626.

20. Cho HJ, Chung JH, Kim IS, Kim HJ, Cho SH, Ki CS, Kim JW. Lack of a genetic association between the CTLA4 gene and Graves' disease in Koreans. Thyroid. 2006; 16:237-241.

21. Weng YC, Wu MJ, Lin WS. CT60 single nucleotide polymorphism of the CTLA-4 gene is associated with susceptibility to Graves' disease in the Taiwanese population. Ann Clin Lab Sci. 2005; 35:259-264.

22. Pawlak-Adamska E, Frydecka I, Bolanowski M, Tomkiewicz A, Jonkisz A, Karabon L, Partyka A, Nowak O, Szalinski M, Daroszewski J. CD28/CTLA-4/ICOS haplotypes confers susceptibility to Graves' disease and modulates clinical phenotype of disease. Endocrine. 2017; 55:186-199.

23. Petrone A, Giorgi G, Galgani A, Alemanno I, Corsello SM, Signore A, Di Mario U, Nistico L, Cascino I, Buzzetti R. CT60 single nucleotide polymorphisms of the cytotoxic T-lymphocyte-associated antigen-4 gene region is associated with Graves' disease in an Italian population. Thyroid. 2005; 15:232-238.

24. Bicek A, Zaletel K, Gaberscek S, Pirnat E, Krhin B, Stopar TG, Hojker S. 49A/G and CT60 polymorphisms of the cytotoxic T-lymphocyte-associated antigen 4 gene associated with autoimmune thyroid disease. Hum Immunol. 2009; 70:820-824.

25. Yang J, Qin Q, Yan N, Zhu YF, Li C, Yang XJ, Wang X, Pandey M, Hou P, Zhang JA. CD40 C/T(-1) and CTLA$4 \mathrm{~A} / \mathrm{G}(49)$ SNPs are associated with autoimmune thyroid diseases in the Chinese population. Endocrine. 2012; 41:111-115.

26. Kimura H, Kato Y, Shimizu S, Takano K, Sato K. Association of polymorphism at position 49 in exon 1 of the cytotoxic T-lymphocyte-associated factor 4 gene with Graves' disease refractory to medical treatment, but not with amiodarone-associated thyroid dysfunction. Thyroid. 2009; 19:975-981.

27. Esteghamati A, Khalilzadeh O, Mobarra Z, Anvari M, Tahvildari M, Amiri HM, Rashidi A, Solgi G, Parivar K, Nikbin B, Amirzargar A. Association of CTLA-4 gene polymorphism with Graves' disease and ophthalmopathy in Iranian patients. Eur J Intern Med. 2009; 20:424-428.

28. Sahin M, Gursoy A, Erdogan MF. Cytotoxic T lymphocyteassociated molecule-4 polymorphism in Turkish patients with Hashimoto thyroiditis. Int J Immunogenet. 2009; 36:103-106.

29. Kalantari T, Mostafavi H, Pezeshki AM, Farjadian S, Doroudchi M, Yeganeh F, Ghaderi A. Exon-1 polymorphism of ctla-4 gene in Iranian patients with Graves' disease. Autoimmunity. 2003; 36:313-316.

30. Yung E, Cheng PS, Fok TF, Wong GW. CTLA-4 gene A-G polymorphism and childhood Graves' disease. Clin Endocrinol (Oxf). 2002; 56:649-653.

31. Kouki T, Gardine CA, Yanagawa T, Degroot LJ. Relation of three polymorphisms of the CTLA-4 gene in patients with Graves' disease. J Endocrinol Invest. 2002; 25:208-213.

32. Park YJ, Chung HK, Park DJ, Kim WB, Kim SW, Koh JJ, Cho BY. Polymorphism in the promoter and exon 1 of the cytotoxic T lymphocyte antigen-4 gene associated with autoimmune thyroid disease in Koreans. Thyroid. 2000; 10:453-459. 
33. Jurecka-Lubieniecka B, Ploski R, Kula D, Krol A, Bednarczuk T, Kolosza Z, Tukiendorf A, Szpak-Ulczok S, Stanjek-Cichoracka A, Polanska J, Jarzab B. Association between age at diagnosis of Graves' disease and variants in genes involved in immune response. PLoS One. 2013; 8:e59349.

34. Namo Cury A, Longui CA, Kochi C, Calliari LE, Scalissi N, Salles JE, Neves Rocha M, Barbosa de Melo M, Rezende Melo M, Monte O. Graves' disease in Brazilian children and adults: lack of genetic association with CTLA-4 $+49 A>G$ polymorphism. Horm Res. 2008; 70:36-41.

35. Hadj Kacem H, Bellassoued M, Bougacha-Elleuch N, Abid M, Ayadi H. CTLA-4 gene polymorphisms in Tunisian patients with Graves' disease. Clin Immunol. 2001; 101:361-365.

36. Kouki T, Sawai Y, Gardine CA, Fisfalen ME, Alegre ML, DeGroot LJ. CTLA-4 gene polymorphism at position 49 in exon 1 reduces the inhibitory function of CTLA-4 and contributes to the pathogenesis of Graves' disease. J Immunol. 2000; 165:6606-6611.

37. Heward JM, Allahabadia A, Armitage M, Hattersley A, Dodson PM, Macleod K, Carr-Smith J, Daykin J, Daly A, Sheppard MC, Holder RL, Barnett AH, Franklyn JA, et al. The development of Graves' disease and the CTLA-4 gene on chromosome 2q33. J Clin Endocrinol Metab. 1999; 84:2398-2401.

38. Nordyke RA, Gilbert FI Jr, Harada AS. Graves' disease. Influence of age on clinical findings. Arch Intern Med. 1988; 148:626-631.
39. Hou X, Mao J, Li Y, Li J, Wang W, Fan C, Wang H, Zhang $\mathrm{H}$, Shan Z, Teng W. Association of single nucleotide polymorphism rs3792876 in SLC22A4 gene with autoimmune thyroid disease in a Chinese Han population. BMC Med Genet. 2015; 16:76.

40. Kimkong I, Hirankarn N, Nakkuntod J, Kitkumthorn N. Tumour necrosis factor-alpha gene polymorphisms and susceptibility to oral lichen planus. Oral Dis. 2011; 17:206209.

41. Wang CY, Podolsky R, She JX. Genetic and functional evidence supporting SUMO4 as a type 1 diabetes susceptibility gene. Ann N Y Acad Sci. 2006; 1079:257-267.

42. Oaks MK, Hallett KM, Penwell RT, Stauber EC, Warren SJ, Tector AJ. A native soluble form of CTLA-4. Cell Immunol. 2000; 201:144-153.

43. Anjos S, Nguyen A, Ounissi-Benkalha H, Tessier MC, Polychronakos C. A common autoimmunity predisposing signal peptide variant of the cytotoxic T-lymphocyte antigen 4 results in inefficient glycosylation of the susceptibility allele. J Biol Chem. 2002; 277:46478-46486.

44. Sawyer TH, Caskey CT, Bucknall WE. Quantitation and characterization of alphal-antitrypsin in amniotic fluid from first trimester pregnancies. Birth Defects Orig Artic Ser. 1976; 12:303-308.

45. Ban Y, Davies TF, Greenberg DA, Kissin A, Marder B, Murphy B, Concepcion ES, Villanueva RB, Barbesino G, Ling V, Tomer Y. Analysis of the CTLA-4, CD28, and inducible costimulator (ICOS) genes in autoimmune thyroid disease. Genes Immun. 2003; 4:586-593. 